\title{
Purification of raw palygorskite: a comparative study involving different processes and dispersing agents
}

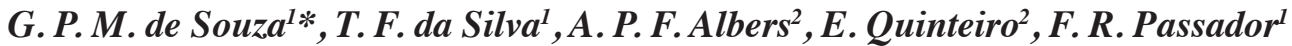 \\ ${ }^{I}$ Federal University of São Paulo, Polymer and Biopolymer Technology Laboratory, \\ 330 Talim St., 12231-280, São José dos Campos, SP, Brazil \\ ${ }^{2}$ Federal University of São Paulo, Ceramic Technology Laboratory, São José dos Campos, SP, Brazil
}

\begin{abstract}
Palygorskite (Pal) is a natural clay mineral with fibrous morphology and high surface area. Depending on the geological origin, it presents impurities, such as quartz and carbonates, which can harm some of its properties. Therefore, this work seeks to define a viable methodology for the purification of a Brazilian Pal. Two types of mixing processes (sonication and milling) and two types of dispersing agents (sodium silicate and sodium polyacrylate) were investigated. In addition, a subsequent acid activation with hydrogen peroxide and sulfuric acid was performed for complete purification. The viability of the purification of Pal was confirmed by X-ray diffraction, X-ray fluorescence, and thermogravimetric analyses. The sonication mixture process and the use of sodium polyacrylate as a dispersing agent were more effective. In addition, BET analysis showed an increase in the surface area of Pal, and scanning electron microscopy confirmed the permanence of its fibrous morphology after the purification steps.
\end{abstract}

Keywords: palygorskite, clay, impurities, purification.

\section{INTRODUCTION}

Palygorskite (Pal) or attapulgite is a hydrous Mg- and Al-rich silicate clay mineral which has a 2:1 phyllosilicate structure with two sheets of $\mathrm{SiO}_{4}$ tetrahedra joined by a central $\mathrm{Mg}, \mathrm{Al}-(\mathrm{O}, \mathrm{OH})$ octahedral sheet [1]. The tetrahedral sheets are continuous, but unlike other phyllosilicates, Pal lacks continuous octahedral sheets. This structural arrangement presents large tunnels parallel to the phyllosilicate ribbons which are partially occupied by water molecules and measure 3.7x6.0 $\AA$ in cross-section [1]. The Pal structure scheme was first studied by Bradley [2] in 1940, having the theoretical formula of $\left(\mathrm{OH}_{2}\right)_{4}(\mathrm{OH})_{2} \mathrm{Mg}_{5} \mathrm{Si}_{8} \mathrm{O}_{20} \cdot 4 \mathrm{H}_{2} \mathrm{O}$ (Fig. 1a). Soils of this clay are found mainly in arid and semi-arid zones of the world [3]. In Brazil, the main deposits are located in the municipality of Guadalupe-PI (Fig. 1b), covering an area of around $700 \mathrm{~km}^{2}$ [4]. The largest deposits present in the Earth's crust of minerals from the group of paligorkites-sepiolites were formed either by the chemical sedimentation of these clay minerals in lakes and inland seas, or by the hydrothermal alteration of volcanic sediments, basaltic glass, or clays in open seas, or even by direct crystallization in calcareous soils [5]. The Pal located in the Brazilian State of Piauí, especially in the region of the municipality of Guadalupe, presents a series of associated minerals and they are associated with magnesium and calcium carbonates, manganese minerals, chalcedony, and remnants of gastropods marine shells, indicating a probable genesis of formation in the marine environment [6]. These sediments were subjected to a high

*gsouza091@gmail.com

Dhttps://orcid.org/0000-0001-8032-3536 alkaline environment and can result, beyond the formation of Pal, magnesium carbonates at significant levels [7]. Pal has a fibrous morphology with free channels where water, ions, and small polar molecules can be located. Because of its structural characteristics, $\mathrm{Pal}$ has interesting properties such as high specific surface area, high sorption, bleaching power, thixotropic properties in the presence of electrolytes, and low surface charges [8-10]. Despite its good properties, $\mathrm{Pal}$, as a mineral clay, generally presents impurities between particles, such as organic matter and the associated mineral mentioned above, like quartz, mica, calcite, and dolomite [6]. These impurities are detrimental to the properties, requiring the purification of the clay for its use in a specific application. There are numerous industrial applications for $\mathrm{Pal}$, such as in oil well drilling fluids [11], vegetable and mineral oil bleach [12], industrial adsorbents [13], refining and chemical processing of petroleum derivatives [14], filler for various industrial products [15], catalyst support [16], and nanocomposites [10].

The sedimentation method followed by acid activation can be used to remove the Pal impurities. In sedimentation, water-based suspensions with the addition of dispersing agents are required. The dispersants most used in the ceramic industry are based on sodium, such as sodium polyacrylate and sodium silicate. The sodium polyacrylate macromolecules have the characteristic of replacing the polar molecules of water that are weakly adsorbed in the phyllosilicate sheets, promoting the fluidity of the material. Therefore, the chains generate a double electrical layer, providing high energy of repulsion [17]. Sodium silicate has the function of neutralizing the reactivity between the particles, due to the high surface energies that they present 


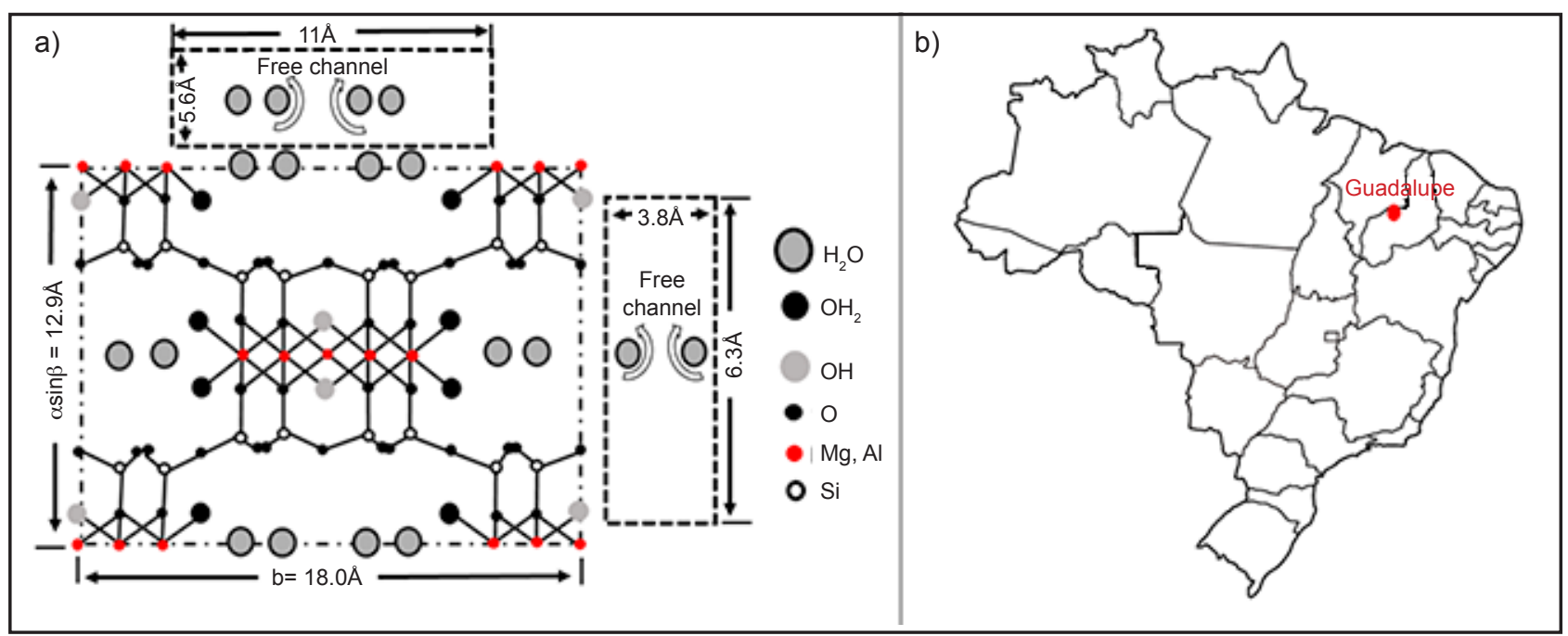

Figure 1: Chemical structure of Pal (a) and map of Brazil showing the location of the municipality of Guadalupe-PI (b).

in ceramic powders when in a liquid medium. Van der Waals forces act to destabilize the suspensions by forming agglomerates, in this way, sodium silicate acts in the opposite direction to these forces [18]. The sedimentation method is based on the difference between the density and/or particle size of minerals to promote the separation between them. In this way, a mixing process combined with the action of dispersing agents aims to break agglomerates, leaving the $\mathrm{Pal}$ particles in suspension while the quartz and other impurities settle in the bottom. From this, through physical separation methods, the non-Pal particles can be removed [8, 19]. To remove remaining organic matter and carbonates, acid activation can be done by using oxidizing reagents, such as hydrogen peroxide $\left(\mathrm{H}_{2} \mathrm{O}_{2}\right)$ and strong acids, as hydrochloric acid $(\mathrm{HCl})$ and sulfuric acid $\left(\mathrm{H}_{2} \mathrm{SO}_{4}\right)[20,21]$. The acid activation allows the improvement of the physicochemical properties of the clay, such as adsorption, specific surface area, cation exchange capacity, among others [22, 23]. In this process, the role of hydrogen peroxide is to oxidize organic matter while acids react with carbonates. With the acid activation, the soluble salts are partially dissolved, resulting in a reduction of iron and aluminum levels while sodium and potassium ions go into solution unless they are present in the silicate structure. The calcium ion present is totally or partially solubilized, while the magnesium ion can remain almost entirely in the clay [20]. For example, considering the acid washing process using sulfuric acid, it reacts with the calcium and magnesium carbonates (Reactions A and B). In this way, the formed salts and other impurities are removed, resulting in a purified Pal.

$$
\begin{aligned}
& \mathrm{CaCO}_{3}+\mathrm{H}_{2} \mathrm{SO}_{4} \rightarrow \mathrm{CaSO}_{4}+\mathrm{H}_{2} \mathrm{O}+\mathrm{CO}_{2} \\
& \mathrm{MgCO}_{3}+\mathrm{H}_{2} \mathrm{SO}_{4} \rightarrow \mathrm{MgSO}_{4}+\mathrm{H}_{2} \mathrm{O}+\mathrm{CO}_{2}
\end{aligned}
$$

Some works have studied the purification of Pal using different conditions. Neto et al. [20] used Pal from different deposits in Guadalupe (Brazil). Acid activation was carried out in solutions between 1 and $7 \mathrm{M} \mathrm{HCl}$ at $70{ }^{\circ} \mathrm{C}$ for different periods $(0.5$ to $7 \mathrm{~h})$. The best result occurred for clays treated at $7 \mathrm{M} \mathrm{HCl}$ for $7 \mathrm{~h}$. No structural changes were observed for $\mathrm{Pal}$ and surface areas above $200 \mathrm{~m}^{2} / \mathrm{g}$ were reached. The authors also achieved a reduction in the quartz content due to a previous processing step (pre-hydration/scrubbing). The achieved quartz content was within the specifications for the use of $\mathrm{Pal}$ in the pharmaceutical market. Barrios et al. [22] treated $\mathrm{Pal}$ with different acid concentrations ranging from 1 to $7 \mathrm{M} \mathrm{HCl}$ for $1 \mathrm{~h}$ at room temperature. Clay treated in 7 $\mathrm{M} \mathrm{HCl}$ was leached. Pal treated with $5 \mathrm{M} \mathrm{HCl}$ provided the best result with the maintenance of the crystalline structure of the clay and gain in surface area $\left(280 \mathrm{~m}^{2} / \mathrm{g}\right)$. Boudriche et al. [24] performed the activation of $\mathrm{Pal}$ with $\mathrm{HCl}(0.5,1,3$, and $5 \mathrm{M}$ ). The authors observed that in low concentrations of $\mathrm{HCl}(\leq 1 \mathrm{M})$, the morphology and crystalline structure of $\mathrm{Pal}$ are preserved and the dissolution of carbonates occurs. However, no studies were found about the purification of Pal using and comparing different types of mixing processes and dispersing agents along with acid activation.

In this work, the search for highly purified Pal aimed its use as nanofillers in nanocomposites, which has been of great interest in recent years [25]. In our previous work [10], polyamide 12 (PA12)/raw Pal nanocomposites were prepared using a high-speed thermokinetic homogenizer. The addition of different contents of raw Pal allowed a certain level of improvement in the mechanical properties, however, there was no adequate dispersion in the matrix, compromising the performance of the materials. Thus, it is expected that the use of mineral clay with great purity can improve its dispersion and the mechanical properties of nanocomposites. Therefore, the main objective of this work is to compare different mixing processes (sonication and milling) and the use of different types of dispersing agents (sodium polyacrylate and sodium silicate) to obtain $\mathrm{Pal}$ water-based suspensions, to be used in the sedimentation and acid activation processes, in order to describe an effective and viable protocol for the purification of a Brazilian Pal. 


\section{EXPERIMENTAL}

Materials: the following materials were used: i) palygorskite (Pal, BRM F 14-EPA 13.04, Brasil Minas) with a density of $2.00-2.25 \mathrm{~g} / \mathrm{cm}^{3}$, retention in 325 mesh sieve (nominal opening of $45 \mu \mathrm{m}$ ) $<10 \mathrm{wt} \%$ and $\mathrm{pH} 7.0$ to 11.0 (5 wt \% water solution); ii) sodium polyacrylate (PA, Acumer 9400, Dow Chemical) dispersant with a molecular weight of $3000-4000, \mathrm{pH} 7.0$, solid content of $42 \%$ and viscosity around $600 \mathrm{cP}\left(25^{\circ} \mathrm{C}\right)$; and iii) sodium silicate (SIL, R2252, Diatom Mineração) dispersant with $\mathrm{SiO}_{2} / \mathrm{Na}_{2} \mathrm{O}$ ratio of 2.15-2.4, total solid content of $46.6-49.2 \%$, density of $1.563-1.600 \mathrm{~g} / \mathrm{cm}^{3}$ and viscosity of $900-1350 \mathrm{cP}\left(25^{\circ} \mathrm{C}\right)$.

Methodology: the methodology was based on references $[19,21]$. Raw Brazilian Pal was first sieved through a 325 mesh sieve to remove part of the impurities, such as quartz. Then (step 1), two water-based suspensions with solid contents of 25 and $1 \mathrm{wt} \%$ of Pal and different dispersing agents were prepared, one of them with sodium polyacrylate and the other one with sodium silicate. The suspensions were mixed using two different processes: i) sonication: the suspensions were sonicated for 5 min with an ultrasonic processor (Vibra Cell VCX750, Sonics) with $40 \%$ of intensity; and ii) ball milling: the suspensions were mixed for $30 \mathrm{~min}$, with a rotation of $150 \mathrm{rpm}$, in a ball mill (MA500, Marconi) with a cylindrical jar (1 L), $800 \mathrm{~g}$ of alumina balls (12 mm diameter) and $100 \mathrm{~g}$ of Pal. After the different mixing methods, the suspensions were placed in a recipient to settle for $10 \mathrm{~min}$, the supernatant was removed and then dried at $100{ }^{\circ} \mathrm{C}$ for $12 \mathrm{~h}$. In step 2, the dried materials, as well as the raw Pal, were subjected to an acid activation process to remove the remaining organic matter and carbonate minerals. The activation process was carried out by two procedures. In the first one, $50 \mathrm{~g}$ of Pal were dispersed in a $30 \% \mathrm{v} / \mathrm{v}$ aqueous suspension of $\mathrm{H}_{2} \mathrm{O}_{2}$. The suspension was stirred on a magnetic stirrer for $24 \mathrm{~h}$ with a rotation of $400 \mathrm{rpm}$. Then, the suspension was dried at $100{ }^{\circ} \mathrm{C}$ for $12 \mathrm{~h}$. In the second procedure, $25 \mathrm{~g}$ of Pal treated with $\mathrm{H}_{2} \mathrm{O}_{2}$ were dispersed in a 1 $\mathrm{M}$ solution of $\mathrm{H}_{2} \mathrm{SO}_{4}$. The suspension was stirred at $70{ }^{\circ} \mathrm{C}$ for $1 \mathrm{~h}$ on a magnetic stirrer with a rotation of $400 \mathrm{rpm}$. After that, the suspension was washed with distilled water until the $\mathrm{pH}$ was equal to 5 ( $\mathrm{pH}$ of distilled water) using a centrifuge (K14-4000, Kasvi) for $2 \mathrm{~min}$ with a rotation of $3000 \mathrm{rpm}$. Finally, the suspension was dried at $100{ }^{\circ} \mathrm{C}$ for $12 \mathrm{~h}$.

Characterization of Pal: all of the following characterizations were performed on raw Pal and after steps 1 and 2. For the identification of the crystalline phases, an X-ray diffractometer (Ultima IV, Rigaku) was used, with CuK $\alpha$ radiation $(\lambda=1.54056 \AA)$, operating at $0.2 \%$ step and $2 \theta$ ranging from $5^{\circ}$ to $55^{\circ}$. The interlayer spacing (d-spacing) of the phases was calculated using Bragg's equation $(2 \mathrm{~d} \cdot \sin \theta=\mathrm{n} . \lambda)$. From the diffractograms, it was expected to identify crystalline phases and to verify the peak intensities reduction related to the impurities present in the Pal, such as quartz and carbonates, after the purification steps. To analyze the chemical composition of the samples, $\mathrm{X}$-ray fluorescence analysis (XRF) was performed using a spectrometer (Zetium, Malvern Panalytical). The samples were fused with lithium tetraborate and the calibration ROC1 (Rocks) was used. Loss on ignition (LOI) was carried out at $1020{ }^{\circ} \mathrm{C}$ for $2 \mathrm{~h}$. To determine the surface area, the analysis of $\mathrm{N}_{2}$ adsorption by the BET method was used. The tests were performed in a gas sorption analyzer (Nova 4200e, Quantachrome Instr.). The samples were heated to $100{ }^{\circ} \mathrm{C}$ and degassing was carried out for $3 \mathrm{~h}$. It was expected an increase in the surface area of Pal after steps 1 and 2 due to the breakdown of agglomerates and removal of impurities. The thermal stability was evaluated by thermogravimetric analysis (TGA, TG209F1 Iris, Netzsch) from room temperature to $800{ }^{\circ} \mathrm{C}$, with a heating rate of $20{ }^{\circ} \mathrm{C} / \mathrm{min}$ and under a constant nitrogen flow of $20 \mathrm{~mL} \cdot \mathrm{min}^{-1}$. The morphological characterization and particle size measurement of the Pal samples were performed by fieldemission gun scanning electron microscopy (FEG-SEM) using a microscope (MIRA3, Tescan) with a voltage of $10 \mathrm{kV}$.

\section{RESULTS AND DISCUSSION}

$X$-ray diffraction (XRD): Fig. 2 shows the X-ray diffractogram of raw Pal. It was possible to identify three main phases: palygorskite (orthorhombic structure), calcite, and quartz, whose respective crystallographic files are JCPDS 00-031-0783, JCPDS 00-005-0586, and JCPDS 01-085-0794. The main diffraction peaks of Pal occurred at approximately $8.6^{\circ}(10.27 \AA), 19.9^{\circ}$ (4.46 $\AA$ ), and $20.9^{\circ}$ $(4.25 \AA)$. For calcite, the most significant peak was around $29.4^{\circ}$ (3.03 $\AA$ ) and for quartz, it was found at $26.7^{\circ}$ (3.34 $\AA$ ). Similar Pal diffractograms were reported in other studies [4, 10, 26]. Fig. 3a shows the X-ray diffractograms of the Pal purified by the different mixing processes and different types of dispersing agents. Fig. 3b shows the diffractograms of the raw and purified $\mathrm{Pal}$ after the acid activation process. Fig. 4 shows the ratios between the intensities of the most significant peaks of palygorskite (110), quartz (101), and calcite (104). In this way, it was possible to make a semiquantitative analysis related to the amount of each mineral phase present in the Pal, verifying the purification efficiency

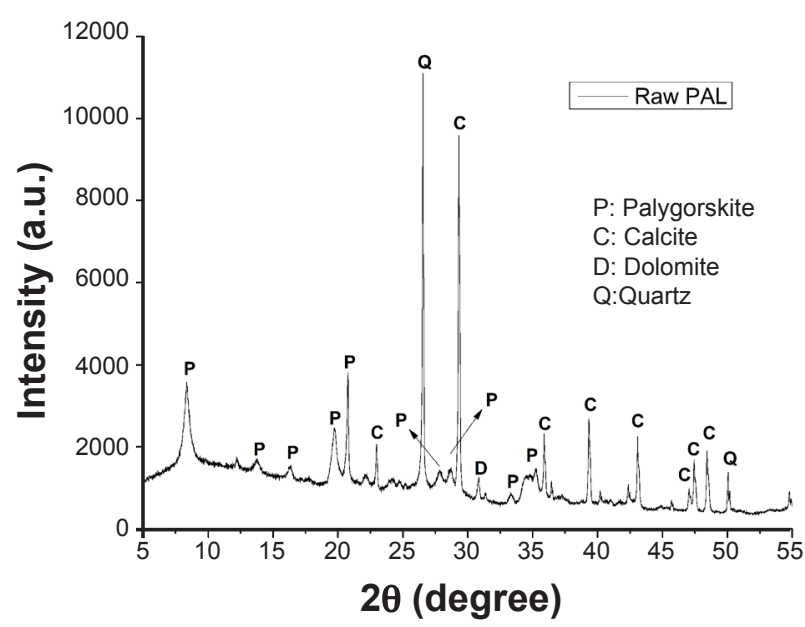

Figure 2: X-ray diffractogram of raw Pal 

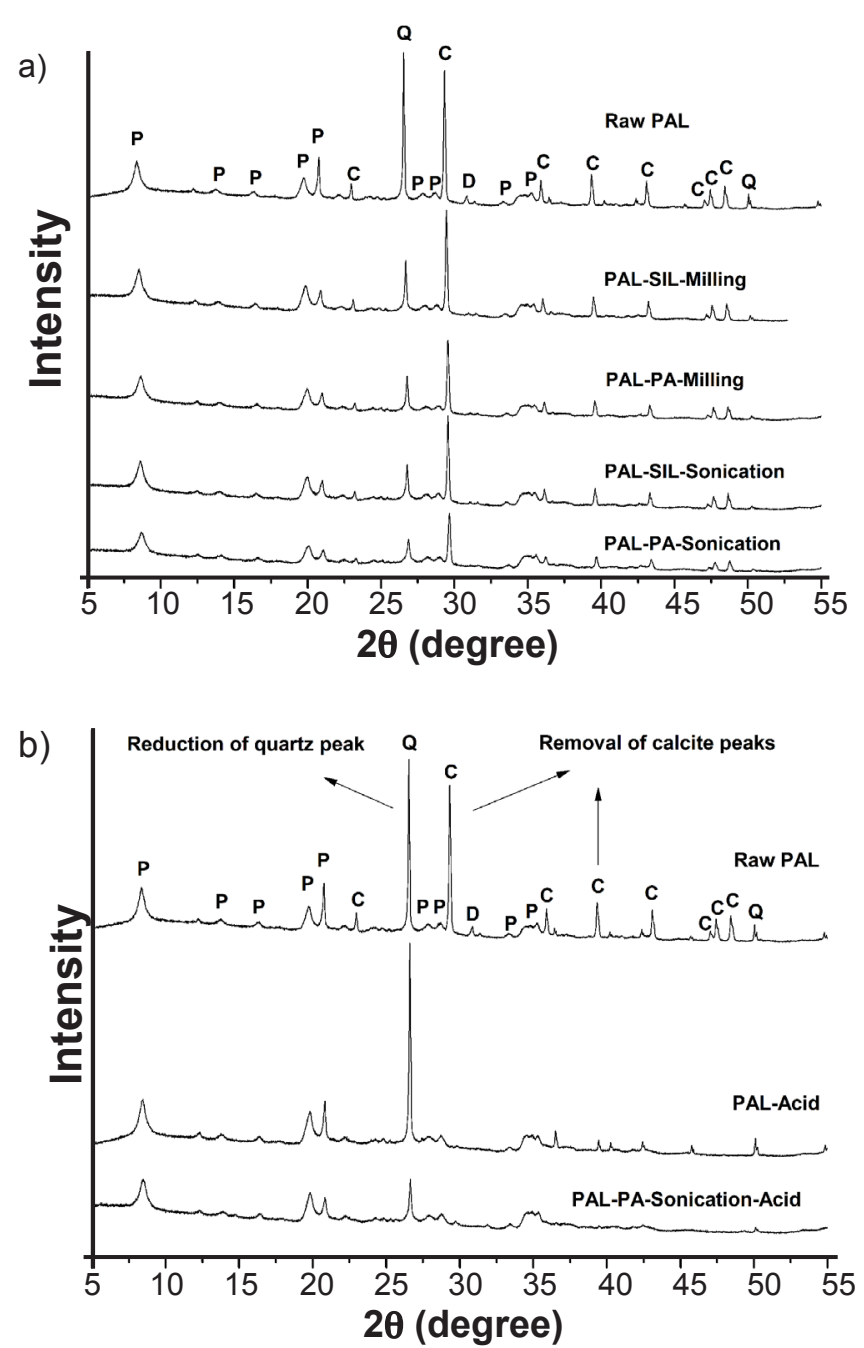

Figure 3: X-ray diffractograms of: a) Pal purified by different mixing processes and different types of dispersant; and b) raw and purified $\mathrm{Pal}$ after acid activation.

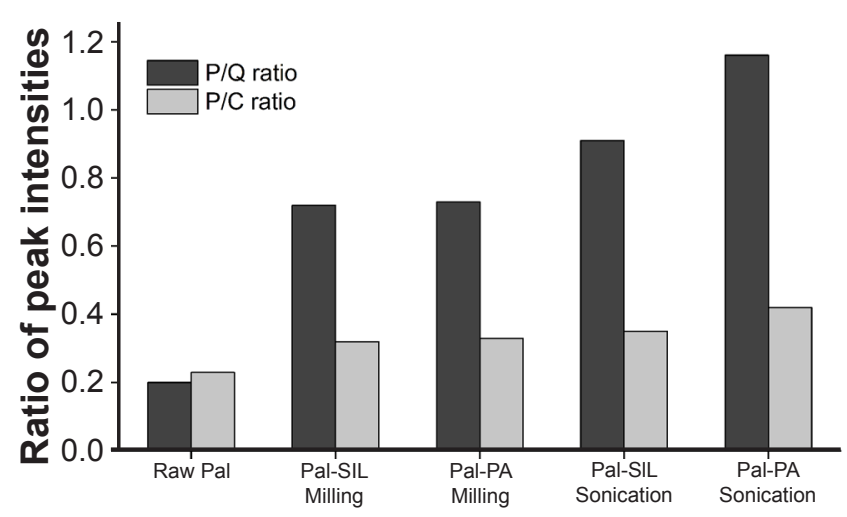

Figure 4: Ratios of peak intensities P/Q and P/C (P: palygorskite; Q: quartz; C: calcite).

of each process. In order to verify the influence of the processes in the structural disorder of these phases, the full width at half maximum (FWHM) of the main peak was also measured (Table I).

Analyzing the diffractograms in Fig. 3a and the ratios of the peak intensities in Fig. 4, it was possible to verify that both mixing processes and different dispersing agents
Table I - Full width at half maximum (2 $\theta$, degree) of XRD peaks of palygorskite $(\mathrm{P})$, quartz $(\mathrm{Q})$, and calcite $(\mathrm{C})$ after different purification steps.

\begin{tabular}{cccc}
\hline Sample & $\mathrm{P}(110)$ & $\mathrm{Q}(101)$ & $\mathrm{C}(104)$ \\
\hline Raw Pal & 0.45 & 0.12 & 0.14 \\
Pal-SIL-Milling & 0.45 & 0.13 & 0.14 \\
Pal-PA-Milling & 0.46 & 0.15 & 0.15 \\
Pal-SIL-Sonication & 0.46 & 0.14 & 0.15 \\
Pal-PA-Sonication & 0.48 & 0.18 & 0.18 \\
Pal-PA-Sonication-Acid & 0.48 & 0.16 & - \\
\hline
\end{tabular}

resulted in reductions of the intensities of quartz and calcite peaks, indicating that these impurities were partially removed from the Pal. Moreover, the peaks related to Pal did not undergo significant changes. Although in some XRD patterns the intensity of the Pal diffraction peak was reduced, there was no significant increase in the structural disorder of the phases, as indicated in Table I by the full width at half maximum (FWHM), in which a very small widening of the peaks in different purification steps was observed. These results indicated that the mixing methods did not destroy its crystalline structure. Finally, comparing the results, it can be concluded that the sonication process and the use of sodium polyacrylate as a dispersing agent were more effective in reducing the quartz and calcite peaks because they enabled a greater breakdown of agglomerates, indicated by the highest values of the $\mathrm{P} / \mathrm{Q}$ and $\mathrm{P} / \mathrm{C}$ ratios $(\mathrm{P}$ : palygorskite; Q: quartz; C: calcite). Concerning dispersing agents, sodium polyacrylate was more efficient in dispersing particles because it had an electrosteric stabilization mechanism while sodium silicate had only an electrostatic stabilization mechanism. The larger molecular chains present in sodium polyacrylate resulted in better dispersion of larger particles. Analyzing the diffractograms in Fig. 3b, where acid activation was performed in the raw and purified Pal with PA-sonication, it is possible to verify the influence of this process in the removal of impurities. In more detail, it was noted that the calcite peaks disappeared completely, which can be explained by the reaction of sulfuric acid with the calcium carbonate, i.e. calcite (Reaction A). In this way, the formed salts and other impurities were removed in the centrifugation process, resulting in a purified Pal, with lower quartz contents and practically no calcite. In addition, the acid activation also did not cause the destruction of the Pal crystalline structure, which, according to some studies, could cause the formation of amorphous silica $[22,24]$.

$X$-ray fluorescence $(X R F)$ : Table II shows the chemical composition by XRF of raw Pal and after the different purification steps. For raw Pal, it was possible to observe the contents of the main oxides in its structure, in addition to the carbonates and other impurities present. From the purified samples, it was possible to confirm the significant reduction of calcite content due to acid activation (from $8.56 \%$ to around $1 \%$ of $\mathrm{CaO}$ ). The removal of quartz was not indicated by the decrease in the $\mathrm{SiO}_{2}$ content, because, 
Table II - Chemical composition by XRF of raw Pal and after different purification steps.

\begin{tabular}{cccccc}
\hline Oxide & Raw Pal & $\begin{array}{c}\text { Pal-SIL-Milling- } \\
\text { Acid }\end{array}$ & $\begin{array}{c}\text { Pal-PA-Milling- } \\
\text { Acid }\end{array}$ & $\begin{array}{c}\text { Pal-SIL- } \\
\text { Sonication-Acid }\end{array}$ & $\begin{array}{c}\text { Pal-PA- } \\
\text { Sonication-Acid }\end{array}$ \\
\hline $\mathrm{SiO}_{2}(\%)$ & 50.8 & 55.8 & 55.8 & 56.0 & 54.5 \\
$\mathrm{Al}_{2} \mathrm{O}_{3}(\%)$ & 11.8 & 14.8 & 15.1 & 14.9 & 14.9 \\
$\mathrm{Fe}_{2} \mathrm{O}_{3}(\%)$ & 5.95 & 7.27 & 7.37 & 7.30 & 7.28 \\
$\mathrm{MnO}(\%)$ & 0.42 & 0.20 & 0.16 & 0.16 & 0.17 \\
$\mathrm{MgO}(\%)$ & 4.47 & 5.14 & 5.22 & 5.35 & 5.20 \\
$\mathrm{CaO}(\%)$ & 8.56 & 1.12 & 0.91 & 0.45 & 1.08 \\
$\mathrm{Na} \mathrm{O}_{2}(\%)$ & $<0.10$ & $<0.10$ & $<0.10$ & $<0.10$ & $<0.10$ \\
$\mathrm{~K}_{2} \mathrm{O}(\%)$ & 2.12 & 2.48 & 2.52 & 2.52 & 2.49 \\
$\mathrm{TiO}_{2}(\%)$ & 0.54 & 0.63 & 0.65 & 0.63 & 0.63 \\
$\mathrm{P}_{2} \mathrm{O}_{5}(\%)$ & $<0.10$ & $<0.10$ & $<0.10$ & $<0.10$ & $<0.10$ \\
$\mathrm{LOI}^{*}(\%)$ & 15.0 & 11.8 & 12.1 & 12.5 & 13.6 \\
\hline
\end{tabular}

* loss on ignition $\left(1020^{\circ} \mathrm{C}\right)$.

in fact, there was an increase from $50 \%$ to around $55 \%$. This result can be explained by the increase in the relative content of Pal, which has mostly silica in its composition. Likewise, there was a slight increase in the contents of $\mathrm{Al}_{2} \mathrm{O}_{3}$ and $\mathrm{Fe}_{2} \mathrm{O}_{3}$, which were also present in the composition of Pal (both $\mathrm{Al}$ and $\mathrm{Fe}$ can make isomorphic substitutions with $\mathrm{Mg}$ [4]). Finally, the purification methods resulted in a decrease in the LOI, since there was a decrease in the organic matter present. However, the decrease was small because most of the LOI at $1020^{\circ} \mathrm{C}$ was due to the loss of structural water and dehydroxylation of Pal.

BET analysis: Table III shows the surface area values of Pal obtained by the BET method in the different purification steps. The raw $\mathrm{Pal}$ showed a value of $119.9 \mathrm{~m}^{2} / \mathrm{g}$, which was in agreement with the results found in the literature for this mineral $[4,8,27]$. After the purification steps, it was observed that all mixing processes and dispersants used, in addition to acid activation, resulted in increases in the surface area value (Table III) because there was an increase of mass fractions of palygorskite, which has a higher surface area compared with other minerals, as well as a breakdown of agglomerates and removal of impurities. Comparing the mixing processes, considering the same dispersant, the sonication process was more efficient to disperse particles and consequently to settle mineral particles that were not mineral clay (Pal), like quartz. This can be supposed because of the higher values of the surface area measured in the sonicated samples, which is in line with the results of XRD that showed a greater efficiency of this process in settle quartz and removing impurities in relation to the milling process. Regarding the dispersing agents, it was expected that the samples purified using sodium polyacrylate as a dispersant would present higher surface area due to its greater efficiency in purifying the Pal as evidenced by XRD analysis (Figs. 3a and 4). However, the samples that used sodium silicate presented the highest surface area. A hypothesis to explain this result is that sodium polyacrylate really is more efficient in deflocculated suspensions, including Pal suspensions, allowing better separation of the mineral clay particles from other minerals, such as quartz and calcite. However, the Pal particles have fibrous morphology, with a great tendency to form agglomerates, consequently reducing the specific surface area obtained in the BET method. The increase in the surface area of Pal after acid activation has also been reported in other studies $[4,22,24]$, in which the increase is attributed to the dissolution of carbonates which produces an increase in the relative proportions of the palygorskite.

Table III - Surface area values of Pal after different purification steps.

\begin{tabular}{cc}
\hline Sample & Surface area $\left(\mathrm{m}^{2} / \mathrm{g}\right)$ \\
\hline Raw Pal & 119.9 \\
Pal-SIL-Milling & 127.1 \\
Pal-PA-Milling & 113.9 \\
Pal-SIL-Sonication & 140.0 \\
Pal-PA-Sonication & 125.4 \\
Pal-SIL-Milling-Acid & 145.3 \\
Pal-PA-Milling-Acid & 127.7 \\
Pal-SIL-Sonication-Acid & 160.6 \\
Pal-PA-Sonication-Acid & 132.3 \\
\hline
\end{tabular}

Thermogravimetric analysis (TGA): Fig. 5a shows the TGA curves of Pal purified by the different mixing processes and different types of dispersing agents and Fig. 5b shows purified Pal after acid activation. Table IV shows the weight loss at each stage of the raw Pal and after the purification steps. From the TGA curve of raw Pal (Fig. 5a), it was possible to verify 4 stages of weight loss. The $1^{\text {st }}$ stage, between 60 and $150{ }^{\circ} \mathrm{C}$, was due to the loss of adsorbed and zeolitic water (2.6\%). In the $2^{\text {nd }}$ stage, between 175 and $350{ }^{\circ} \mathrm{C}$, there was a loss of two coordination water molecules bound to octahedral cations $(1.6 \%)$. In the $3^{\text {rd }}$ stage, between 350 and $550{ }^{\circ} \mathrm{C}$, the condensation of the two remaining coordinated water 

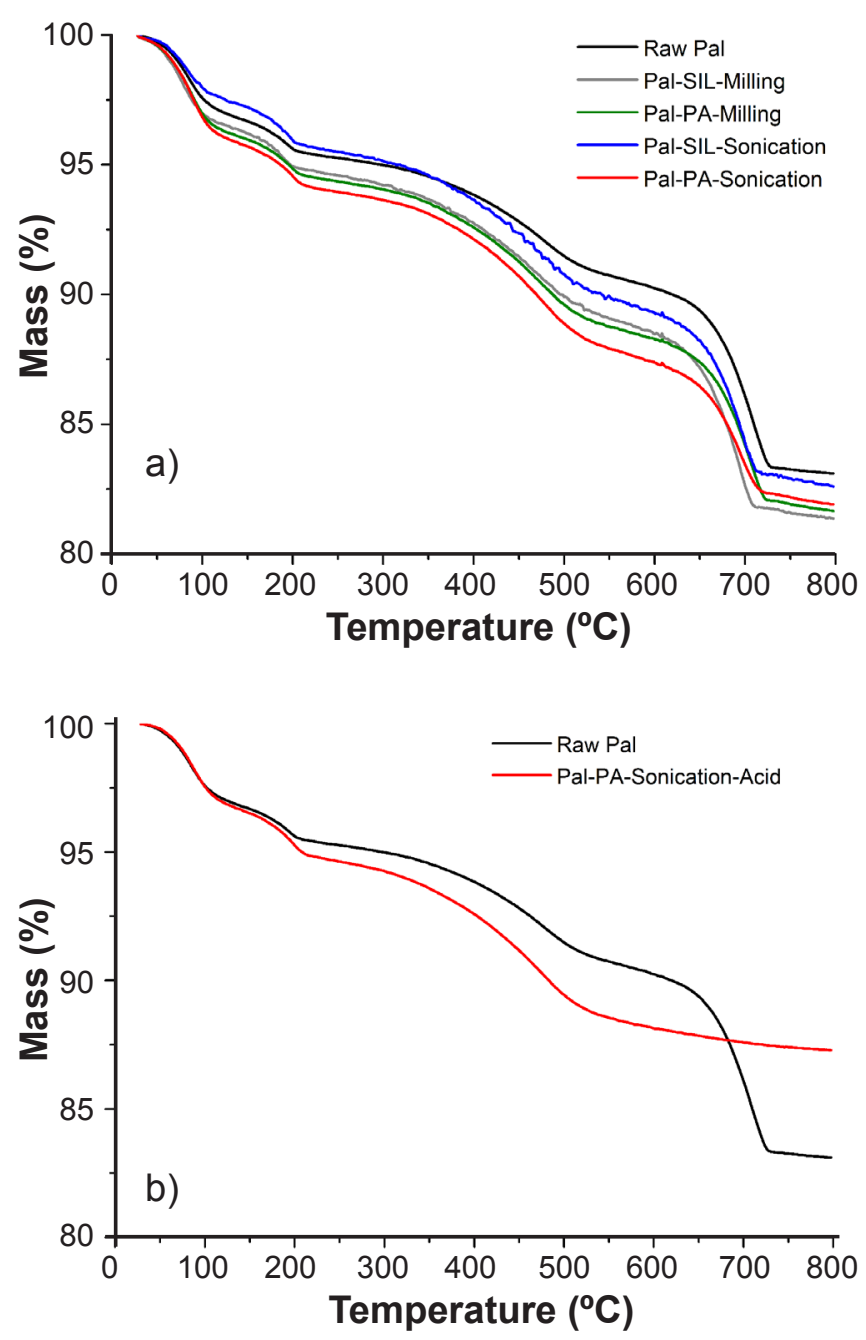

Figure 5: TGA curves of: a) Pal purified by different mixing processes and different types of dispersant; and b) purified $\mathrm{Pal}$ after acid activation.

molecules and hydroxyl groups occurred (4.3\%). Finally, in the $4^{\text {th }}$ stage, above $680{ }^{\circ} \mathrm{C}$, the weight loss came from the decomposition of calcite present in Pal (7.0\%). This thermal degradation behavior of raw $\mathrm{Pal}$ is usually reported in the literature $[1,11,22,28]$, however, the main difference for the raw Brazilian Pal is the higher calcite content. All samples showed similar behavior for TGA with 4 stages of weight loss for both different mixing processes and types of dispersing agents. However, the TGA curve for raw Pal was shifted upwards because the weight losses for stages 1, 2, and 3 were smaller (Table IV), probably due to the presence of flake aggregates and therefore the thermal decomposition reactions were not fully completed. On the other hand, the sample Pal-PA-Sonication showed higher weight losses in stages 1 to 3 and less weight loss for stage 4 (corresponding to the decomposition of calcite), which indicated a lower amount of impurities, since stages 1 to 3 were from water molecules and hydroxyl groups inherent to Pal. Analyzing the sample of the Pal purified using the PA-sonication method and later treated with acid activation (Fig. 5b), it was possible to notice the absence of the $4^{\text {th }}$ stage of decomposition. This result was another indication
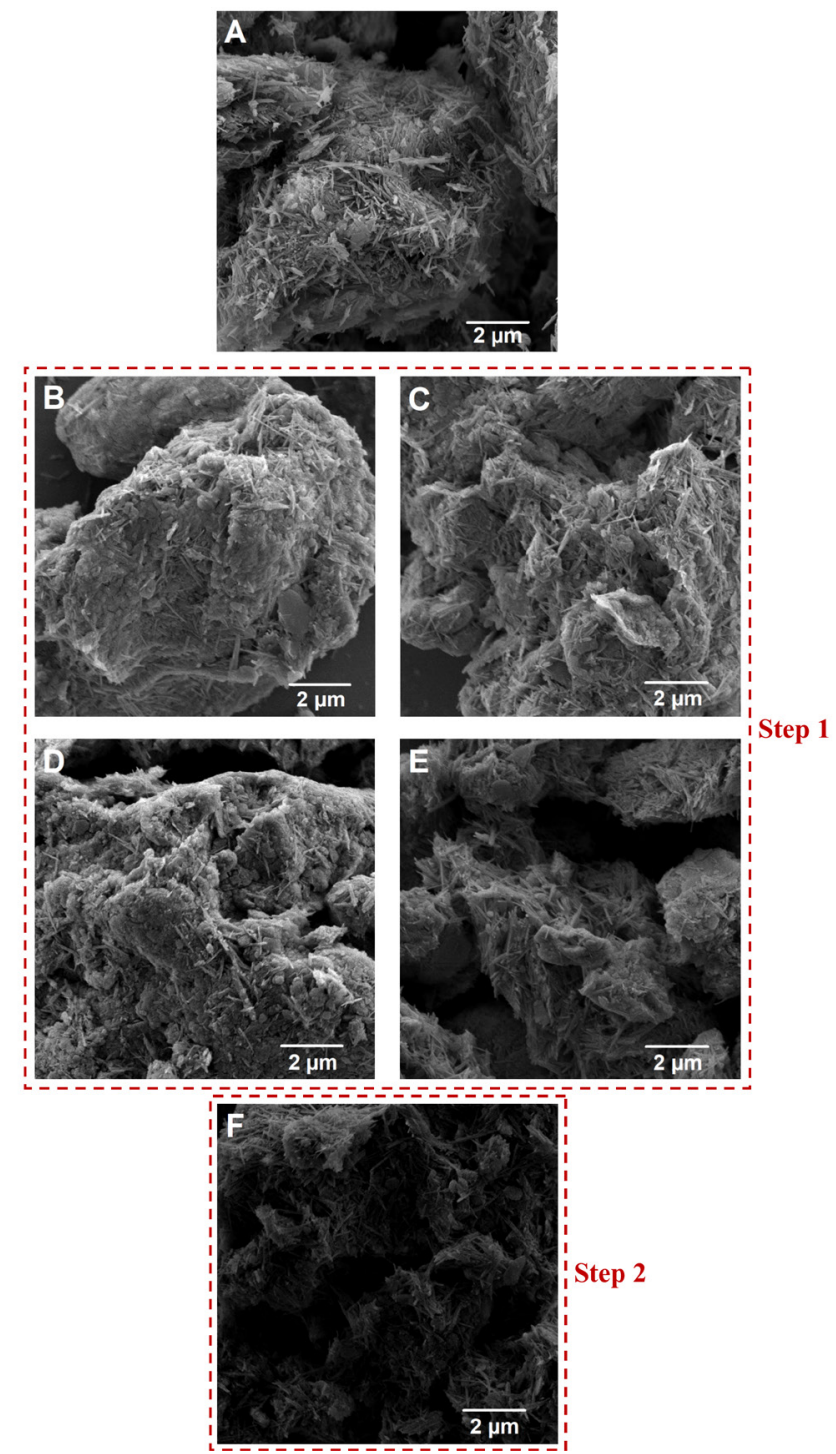

Figure 6: FEG-SEM micrographs of: a) raw Pal; b) Pal-PA-Milling; c) Pal-PASonication; d) Pal-SIL-Milling; e) Pal-SIL-Sonication; and f) Pal-PA-SonicationAcid.

of the efficiency of the reaction of $\mathrm{H}_{2} \mathrm{SO}_{4}$ with calcite and its consequent removal from Pal. Also, the higher residual mass value $(87.3 \%)$ was due to the lower amount of organic matter, which was removed through oxidation with hydrogen peroxide.

Morphological characterization: Fig. 6 shows the FEG-SEM micrographs of the raw Pal and the micrographs after the purification steps. In raw Pal (Fig. 6a), it was possible to observe its fibrous morphology of rod crystals with lengths between 0.5 to $4 \mu \mathrm{m}$, with the predominance of rod crystals with a length of $1 \mu \mathrm{m}$. Aggregates were also observed, formed due to the electrostatic and van der Waals forces among the rod crystals, causing a strong tendency for particle agglomeration. The morphology observed for Pal was similar to that found in other works $[23,29,30]$. It is interesting to note that it was not possible to identify particles of quartz or calcite using FEG-SEM, neither by size nor by morphology. Comparing the milling and sonication processes, it was possible to verify a 
Table IV - Weight loss (\%) at each stage of raw Pal and after purification steps.

\begin{tabular}{cccccc}
\hline Sample & Stage 1 & Stage 2 & Stage 3 & Stage 4 & Residual mass \\
\hline Raw Pal & 2.6 & 1.6 & 4.3 & 7.0 & 83.1 \\
Pal-SIL-Milling & 3.4 & 2.2 & 4.1 & 6.3 & 81.4 \\
Pal-PA-Milling & 3.8 & 1.8 & 4.9 & 6.5 & 81.7 \\
Pal-SIL-Sonication & 2.6 & 2.0 & 4.2 & 6.4 & 82.6 \\
Pal-PA-Sonication & 4.1 & 1.8 & 5.2 & 5.2 & 81.9 \\
Pal-PA-Sonication-Acid & 3.0 & 2.0 & 5.3 & 0 & 87.3 \\
\hline
\end{tabular}

higher agglomeration for the milling process, which was in agreement with the results of XRD and BET. In addition, the lengths of the Pal rod crystals did not show significant differences for all samples, indicating that the mixing processes did not cause breakage of the rod crystals. Regarding the type of dispersing agent used, there were also no significant differences between the morphologies. Finally, analyzing the purified Pal with PA-Sonication-Acid (Fig. 6f), it was observed that the acid activation did not destroy the Pal crystalline structure. It is interesting to note that, according to some works $[22,24]$, even with the formation of amorphous silica, which was not observed in the XRD pattern, the fibrous morphology of $\mathrm{Pal}$ is still preserved. Therefore, removing impurities, increasing the surface area, and preserving the main morphological characteristics of raw $\mathrm{Pal}$ (fibrous morphology), possibly result in gains in its physicochemical properties.

\section{CONCLUSIONS}

Comparing the different mixing processes and dispersing agents, in addition to a subsequent acid activation, it was enabled to verify that the association of sonication mixing process and the use of sodium polyacrylate as a dispersant, followed by acid activation, was the best methodology to reach the highest efficiency in the purification of a Brazilian palygorskite clay $(\mathrm{Pal})$. The sonication process was a fast and easy method for mixing, and the best result was that the fibrous morphology of Pal was preserved, corroborated in the micrographs obtained by FEG-SEM. Sodium polyacrylate, which combined the steric and electrostatic stabilization effects, presented a better performance to break agglomerates, leaving the Pal particles in suspension while the quartz and other impurities settled in the bottom, allowing to reduce the quartz content. The acid activation was responsible for the removal of calcite, evidenced by XRD patterns with no peaks related to this phase and by the high reduction of $\mathrm{CaO}$ content according to the XRF analysis; moreover, the acid activation provided an increase in the surface area for all methods employed. According to the purification methodology presented, it was possible to obtain a material with better properties, enabling its use in several applications that require clay minerals with high purity.

\section{ACKNOWLEDGMENTS}

The authors are grateful to CNPq (Conselho Nacional de Desenvolvimento Científico e Tecnológico, process 310196/2018-3 and 405675/2018-6) for the financial support. This study was financed in part by the Coordenação de Aperfeiçoamento de Pessoal de Nível Superior-Brazil (CAPES) - Finance Code-001. The authors are also grateful to Brasil Minas for the donation of palygorskite and Diatom Mineração Ltda. for supplying the sodium silicate dispersant. The authors also thank Dr. Tiago Moreira Bastos Campos and INPE for the FEG-SEM images.

\section{REFERENCES}

[1] J.E. Post, P.J. Heaney, Am. Mineral. 93, 4 (2008) 667.

[2] W.F. Bradley, Am. Mineral. 25, 6 (1940) 405.

[3] A. Neaman, A. Singer, Geoderma 123, 3-4 (2004) 297.

[4] K.C.M. Xavier, E.C. Silva Filho, M.S.F. Santos, M.R.M.C. Santos, A.B. da Luz, Holos 5 (2012) 60.

[5] A. Singer, E. Galan (Eds.), "Palygorskite-sepiolite: occurrences, genesis and uses", Elsevier, Amsterdam (1984) 352.

[6] A.B. da Luz, F.A.F. Lins, Rochas e minerais industriais: usos e especificações, CETEM-MCT, Rio Janeiro (2008).

[7] L.P. Ribeiro, Geochim. Bras. 10, 2 (1996) 401.

[8] W.L. Haden, I.A. Schwint, Ind. Eng. Chem. 59, 9 (1967) 58.

[9] E. Galan, Clay Miner. 31, 4 (1996) 443.

[10] T. Ferreira, G. Ferreira, D.M. Morgado, T. Larissa, SN Appl. Sci. 2 , 3 (2020) 369.

[11] C.A.M. Baltar, A.B. da Luz, L.M. Baltar, C.H. de Oliveira, F.J. Bezerra, Appl. Clay Sci. 42, 3-4 (2009) 597.

[12] J. Huang, Y. Liu, Y. Liu, X. Wang, J. Am. Oil Chem. Soc. 84, 7 (2007) 687.

[13] D.N. Taha, I.S. Samaka, L.A. Mohammed, J. Asian Sci. Res. 3, 9 (2013) 945.

[14] S. Zhang, Y. Zhang, X. Su, Y. Zhang, Chem. Res. Chin. Univ. 29, 1 (2013) 37.

[15] N.A.M. Nor, N. Othman, Procedia Chem. 19 (2016) 351.

[16] R. Shan, J. Shi, B. Yan, G. Chen, J. Yao, C. Liu, Energy Convers. Manag. 116 (2016) 142.

[17] F.S. Ortega, V.C. Pandolfelli, J.A. Rodrigues, P. Sepulveda, Cerâm. Ind. 2, 5-6 (1997) 34. 
[18] A. Stempkowska, J. Mastalska-Popławska, P. Izak, L. Ogłaza, M. Turkowska, Appl. Clay Sci. 146 (2017) 147.

[19] R.J. Purcell Jr., D.C. Parker, "Purified attapulgite clay", US Patent 6444601 B1 (2012).

[20] J.P. Neto, S.L.M. de Almeida, R.M. Carvalho, in "Tecnologia mineral", 64, CETEM, Brazil (1993) 1.

[21] R.N. Oliveira, W. Acchar, G.D.A. Soares, L.S. Barreto, Mater. Res. 16, 4 (2013) 924.

[22] M.S. Barrios, L.V.F. González, M.A.V. Rodríguez, J.M.M. Pozas, Appl. Clay Sci. 10, 3 (1995) 247.

[23] M. Myriam, M. Suarez, J.M. Martin-Pozas, Clays Clay Miner. 46, 3 (1998) 225.

[24] L. Boudriche, R. Calvet, B. Hamdi, H. Balard, Colloids
Surf. A Physicochem. Eng. Asp. 392, 1 (2011) 45.

[25] W. Wang, A. Wang, Appl. Clay Sci. 119 (2016) 18.

[26] C. Tao, W. Hejing, Z. Xiaoping, Z. Nan, Acta Geol. Sin. 82, 2 (2010) 385.

[27] R.M. Barrer, N. Mackenzie, J. Phys. Chem. 58, 7 (1954) 560.

[28] R. Wang, Z. Li, Y. Wang, W. Liu, L. Deng, W. Jiao, F. Yang, Polym. Compos. 34, 1 (2013) 22.

[29] Y. Nathan, Isr. J. Chem. 6, 3 (1968) 275.

[30] H. Yang, A. Tang, J. Ouyang, M. Li, S. Mann, J. Phys. Chem. B 114, 7 (2010) 2390.

(Rec. 11/06/2020, Rev. 16/07/2020, 17/09/2020, Ac. $01 / 11 / 2020)$ 